\title{
BASSNETT, SUSAN. REFLECTIONS ON TRANSLATION. BRISTOL, UK: MULTILINGUAL MATTERS, 2011. 193 P.
}

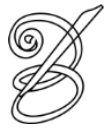 \\ Camila Paula Camilotti ${ }^{1}$ \\ (Doutoranda - UFSC-Florianópolis/SC/Brasil) \\ kamillapc@yahoo.com.br \\ Iliane Tecchio $^{2}$ \\ (Doutoranda - UFSC-Florianópolis/SC/Brasil) \\ Iliane.tecchio@gmail.com
}

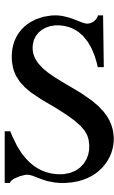

usan Bassnett atua como teórica dos Estudos da Tradução e docente de Literatura Comparada na Universidade de Warwick. Publicou cerca de 20 livros que se tornaram pilares no âmbito da crítica literária e dos Estudos da Tradução. Dentre os principais,

citamos: Translation Studies (1980), Comparative Literature (1993), Translation, History, and Culture (1996), The Translator as a Writer (2008), Translation in Global News (2008) e Political Discourse, Media and Translation (2011).

O livro Reflections on Translation, publicado em junho de 2011, é resultado de uma coletânea de 39 textos escritos pela autora ao longo de 10 anos de estudo e pesquisa em tradução.

O Capítulo 1 aborda a temática da identidade do tradutor e do fato de que as teorias da tradução, preocupadas em desvendar os segredos desse campo disciplinar, negligenciam a questão da subjetividade do tradutor. O Capítulo 2 relata a problemática da tradução literal. Bassnett afirma que esta tem sido o pecado original dos Estudos da Tradução. Ela argumenta que a divergência entre diferentes línguas leva à impossibilidade da existência de uma tradução literal clara e compreensível.

O Capítulo 3 apresenta a dualidade entre teoria e prática, o qual baseia seus questionamentos no quanto a teoria pode auxiliar a atividade tradutória e vice-versa. No texto seguinte, a pesquisadora reflete sobre a ameaça que o tradutor, por muito tempo, representou para a sociedade e que ainda representa para alguns países orientais. Bassnett defende que o tradutor merece um lugar privilegiado na sociedade e na ciência da tradução. 
O Capítulo 5 discute sobre a modernização da tradução derivada do constante movimento da língua. Bassnett adverte que o tradutor deve encontrar um equilíbrio entre a língua tradicional e a moderna, com ciência de quando inovar e quando deixar como está na obra fonte.

O Capítulo 6 atenta para o modo equivocado que as pessoas leigas em tradução consideram o processo tradutório: uma tarefa simples e fácil. Bassnett sublinha que traduzir é um processo complexo, que envolve análise, escolhas e tomadas de decisões. A pesquisadora segue essa temática no capítulo procedente, quando pontua que grandes períodos de inovação e mudança na escrita estão associados com a tradução de alguma forma; e no Capítulo 8, aconselha os tradutores a pesquisarem as variáveis significativas que determinadas palavras podem carregar, sobretudo quando se trata de sinônimos. Bassnett sugere dicionários como principal referência por acompanhar a evolução da língua.

A problemática da tradução versus adaptação é apresentada no Capítulo 9. Bassnett admite ser essa uma questão confusa e que acontece em decorrência da ideia errônea que ainda se tem de tradução. Traduzir não é um simples processo de transferência linguística, mas sim, uma atividade que exige leitura cuidadosa e escrita habilidosa.

No Capítulo 10, Bassnett salienta o estilo do tradutor. Sendo um processo semelhante ao da escrita, a tradução envolve um exercício de tomada de decisões, reestruturações e reescrita. Questão paralela é abordada no capítulo seguinte, no qual a autora questiona-se por que o tradutor, sobretudo o de textos literários, e o escritor são considerados duas entidades separadas em nossa cultura. Bassnett afirma que a indivisibilidade entre a escrita e a tradução se torna evidente ao considerarmos que muitos escritores também já tiveram a experiência da tradução.

A autora destaca, no Capítulo 12, que o estudo e a prática da tradução foram, por muito tempo, negligenciados no campo acadêmico e como ainda se encontram às margens da respeitabilidade acadêmica. Outro assunto a respeito da hegemonia linguística é abordado no Capítulo 13, em que Bassnett reflete sobre o fato de as escolas secundárias no Reino Unido decretarem a não obrigatoriedade do ensino de literaturas clássicas estrangeiras e de língua estrangeira a partir de 2008.

O Capítulo 14 trata da problemática da tradução de poesias. Ao traduzir poesias, o tradutor se depara com aspectos de difícil solução, tais como: rima, métrica, ritmo e figuras de linguagem. Percebe-se que esse é um processo complexo que exige tempo e paciência. 
A importância de trabalhar com cautela ao realizar a atividade da tradução e o papel do tradutor para tais fins são questões salientadas no Capítulo 15. Como exemplo, a autora cita o projeto de mídia desenvolvido por Silvio Berlusconi, que fracassou em consequência da péssima qualidade das traduções. A hipótese de Bassnett é que as traduções tenham sido feitas por máquinas, sem a interferência de um tradutor para corrigi-las e organizá-las.

Os capítulos 16 e 17 tratam do conhecimento de mais de uma língua estrangeira. A autora se sentiu instigada com a proposição de que o tradutor deve ter um conhecimento perfeito nas línguas estrangeiras com as quais trabalha. Bassnett afirma que não existe conhecimento perfeito e muito menos em línguas estrangeiras. Ao contrário, é exatamente reconhecer a impossibilidade da perfeição que faz um bom tradutor. No Capítulo 17, a autora descreve sua capacidade de lembrar línguas estrangeiras estudadas há tempos e esquecidas, mas que são reativadas em contato com os países ou com os falantes das línguas em questão. Bassnett busca entender o processo que acontece na mente das pessoas que se encontram nessa situação.

Dando continuidade à abordagem do aprendizado de língua estrangeira, a autora enfatiza que ao aprender uma língua estrangeira, aprendem-se também seus aspectos culturais evidenciados nos gestos e nos costumes. No Capítulo 19, Bassnett esclarece que as diferenças culturais, no que diz respeito a insultos e palavras, é uma questão delicada que deve ser estudada para evitar choques culturais. No âmbito dos Estudos da Tradução, esse ponto pode representar um problema aos tradutores, que devem estar sempre atentos aos termos propensos a serem entendidos como insultos.

Bassnett discorre, no decorrer do Capítulo 20, a propósito das diferentes formas com as quais os tradutores e interpretes abordam um texto, e que a mesma situação acontece com a comunicação oral entre membros de diferentes países que procuram explicar com gestos e palavras para fazer o interlocutor entender a mensagem. A autora conclui que isso é um exemplo clássico de aculturação: fazer o estrangeiro tornar-se familiar, aproximando-o da própria cultura.

No Capítulo 21, Bassnett ressalta a importância do tradutor em possibilitar ao leitor o contato com importantes obras do passado. Ela ilustra seu ponto de vista citando a tradução da obra Sir Gawain and the Green Knight, escrita em 2007 por Simon Armitage. O passado também é abordado no capítulo consecutivo, no qual Bassnett relata o papel das tradutoras na história.

Os capítulos 23, 24 e 25 são dedicados a traduções de peças teatrais. Em linhas gerais, a pesquisadora sublinha que, em razão da natureza colaborativa do teatro, o tradutor deveria 
realizar seu trabalho juntamente com a equipe teatral. Bassnett também destaca que traduzir uma peça teatral envolve muito mais do que transferências de palavras, pois o tradutor precisa traduzir os espaços entre as palavras do texto que será encenado. As publicações relacionadas à tradução teatral são abordadas no Capítulo 25. Bassnett cita a obra Europe on Stage: Translation and Theatre (2005), de Gunilla Anderman, como sendo de substancial valor.

No Capítulo 26, Bassnett discorre sobre o prazer de reencontrar um livro que fez parte das leituras do nosso passado. Mas, ao ler uma nova tradução, a questão da releitura assume um significado diferente, pois, de acordo com a pesquisadora, cada tradutor reformulará o original de uma maneira levemente diferente ou, às vezes, de maneira radical.

No capítulo subsequente, Bassnett escreve a respeito do crescimento do gênero policial e pontua que o boom de produções em várias culturas é um testemunho da habilidade dos tradutores. Ela destaca o livro Culture Bumps: An Empirical Approach to the Translation of Allusions (1997), de Ritva Leppihalme, por citar estratégias que podem auxiliar na tradução de referentes intertextuais.

No Capítulo 28, tem-se a questão que está sempre presente em Estudos da Tradução: o eterno debate sobre a validade ou não da tradução. Bassnett pontua a evidência das perdas em tradução, mas também da existência de ganhos. Ela ilustra esse ponto de vista ao citar sua experiência na tradução dos poemas de Antonio Machado (1875-1939). O poema "Ode to Autumn", de John Keats (1795-1821), é utilizado no capítulo seguinte para exemplificar a tradução de textos para culturas e regiões geográficas diferentes.

A comparação entre traduções é defendida no Capítulo 30 como sendo útil no sentido de revelar quais estratégias e escolhas foram utilizadas e como estas variam ao longo do tempo, além de nos dar uma visão sobre a história da prática da tradução.

Bassnett inicia o Capítulo 31 destacando que, embora o ofício de traduzir exija várias habilidades, este trabalho sério também pode ter algo de divertido, como, por exemplo, na tradução de histórias em quadrinhos, que oportuniza ao tradutor brincar com as palavras, a fim de levar o humor por meio das diferentes culturas. Brincar com palavras é uma habilidade essencial de quem traduz, ressalta Bassnett. O capítulo seguinte tem como temática o trabalho dos tradutores de fatos jornalísticos. A pesquisadora atenta para a necessidade de um estudo investigativo a respeito do modo como um tradutor é contratado para esse ofício e suas condições de trabalho. A pergunta "What Exactly Did Saddam Say?" que intitula o Capítulo 33 foi 
formulada por Bassnett para ilustrar que uma reportagem chega ao público com diferentes traduções, sendo esse fato exemplificado por meio da menção ao julgamento de Saddam em 2004 reportado de diferentes maneiras no meio jornalístico britânico.

No Capítulo 34, Bassnett destaca a resistência dos falantes nativos da língua inglesa em aprender uma língua estrangeira. A autora pontua que a tradução contribui nesse trabalho de preservação cultural, tendo um papel importante em apoiar culturas que se sentem em uma posição marginalizada.

Os capítulos 35, 36 e 37 abordam questões lexicais. Bassnett enfatiza o retorno de nomes de cidades que haviam sido internacionalizados por décadas de colonialismos comerciais, para nomenclaturas locais ou mesmo para uma renomeação que identifica o local com sua história. O Capítulo 36 trata da tradução de palavras relacionadas à fauna e à flora. O dicionário Multilingual Multiscript Plant Name Database é citado para auxiliar na tradução de termos relacionados à alimentação. Bassnett também sugere que o tradutor alie a teoria à prática, isto é, traduza experimentalmente. Por último, temos a questão da formação de novas estruturas familiares que pode trazer dúvidas sobre qual terminologia usar para identificar o grau de parentesco. Bassnett exemplifica algumas diferenças que as línguas carregam quando se trata do uso da linguagem em relações familiares e cumprimentos.

O Capítulo 38 detém um importante assunto, principalmente para alunos de cursos de pósgraduação: a submissão de artigos para publicação. Com base em sua experiência, Bassnett revela que um dos motivos para a rejeição de trabalhos é o fato de refletirem um desequilíbrio entre a teoria e a prática tradutológicas.

Em "The Power of Poetry", último capítulo, Bassnett esboça o trabalho do tradutor através do gênero da poesia. Ela revela que traduzir poesia acentua mais ainda o papel do tradutor como um leitor. Utilizando a tradução de uma poesia do escritor Antonio Machado, a pesquisadora ilustra que traduzir não é apenas uma questão de transferência linguística, e que o tradutor tem um papel relevante nesse processo.

Esse conjunto de 39 ensaios relembra questões do cotidiano de estudantes, pesquisadores de tradução e tradutores profissionais. A apresentação dessas questões por alguém como Bassnett, que, além de pesquisadora, também é tradutora, possibilita vivenciar na prática os ditames teóricos e ampliar os conhecimentos acerca dos Estudos da Tradução. As reflexões levam para novas pesquisas em diversos âmbitos, tais como, teatro, jornalismo e poesia. Além 
disso, essa coletânea de ensaios, que pode interessar, principalmente, a pesquisadores e professores da Tradução, tradutores e profissionais do ensino de línguas estrangeiras, possibilita estudos sobre as diferenças linguísticas e culturais que desafiam os tradutores.

${ }^{1}$ Currículo Lattes em: < http://lattes.cnpq.br/5635193603045624>.

${ }^{2}$ Currículo Lattes em: <http://lattes.cnpq.br/8107808302449279>. 